\title{
Static pelvic obliquity can influence clinical assessment of trunk rotation in idiopathic scoliosis
} T Kotwicki*, A Kubiak and A Szulc

\author{
Address: Department of Pediatric Orthopedics and Traumatology University of Medical Sciences, Poznan, Poland - ul. 28 Czerwca 1956 roku nr \\ 135 61-545 Poznan, 61 545, Poland \\ Email: T Kotwicki* - kotwicki@ump.edu.pl \\ * Corresponding author
}

from 6th International Conference on Conservative Management of Spinal Deformities

Lyon, France. 21-23 May 2009

Published: 14 December 2009

Scoliosis 2009, 4(Suppl 2):O2 doi:I0.I|86/I748-7|6I-4-S2-O2

This abstract is available from: http://www.scoliosisjournal.com/content/4/S2/O2

(C) 2009 Kotwicki et al; licensee BioMed Central Ltd.

\section{Background}

The Bunnell scoliometer is widely used for scoliosis screening; however the cut-off value for the angle of trunk rotation is still debated. It is not clear whether and how much the scoliometer measurements are sensitive to a non-level pelvis.

\section{Study goals}

The aim of this study was to verify whether the angle of trunk rotation is related to the functional pelvic obliquity. To answer this question, we measured the angle of trunk rotation (ATR) in the classical forward bending position while the unlevel pelvis was adjusted with a shoe lift.

\section{Materials and methods}

The ATR was measured in 25 girls with idiopathic scoliosis (study group), age 13 to 19 years (mean $15.6 \pm 1.8$ years) and in 25 healthy girls (control group), age 12 to 16 years (mean $14.2 \pm 0.9$ years). In the study group the Cobb angle revealed curves ranging from $35.0^{\circ}$ to $92.0^{\circ}$ (mean $54.4^{\circ} \pm 18.0^{\circ}$ ) in the lumbar spine and $38.0^{\circ}$ to $93.0^{\circ}$ (mean $60.7^{\circ} \pm 17.3^{\circ}$ ) in the thoracic spine. The Bunnell scoliometer was then used in two positions: sitting and standing, both forward bending positions. The scoliometer readings were noted at four levels of the spine: high thoracic, main thoracic, lumbar and sacral. Then, the measurements were repeated in the same subjects and at the same four levels of the spine, but after leveling the left or the right side of the pelvis using a $1-2 \mathrm{~cm}$ thick shoe lift.

\section{Results}

When compared to the classical forward bending position, the ATRs were significantly different after the shoe lifts were applied. Typical patterns of alternatively raised or lowered ATRs within adjacent spinal levels were also identified. The difference depended on the shoe lift height and on the spinal level: the change was $1.5^{\circ}-4.5^{\circ}$ of rotation within the lumbar spine; $1.2^{\circ}-3.8^{\circ}$ of rotation within the thoracolumbar spine, and $0.7^{\circ}$ to $2.4^{\circ}$ of rotation within the high thoracic spine.

\section{Conclusion}

The measurement of the ATR with the Bunnell scoliometer is affected by a non-level pelvis, especially within the lumbar spine. This should be taken into consideration when using the scoliometer in school screening. 